\title{
ASPECTOS COMUNES DE LAS ESCUELAS DE CHICAGO Y HARVARD EN MATERIA DE LIBRE COMPETENCIA: EL APORTE DEL NEOINSTITUGIONALISMO*
}

\section{COMMON ASPECTS OF THE CHICAGO AND HARVARD SCHOOLS OF ANTITRUST ANALYSIS: THE NEO-INSTITUTIONAL CONTRIBUTION}

\author{
Jesús Alfonso Soto PINEDA** \\ Luis Felipe JARAMILLO DE LOS RÍOS***
}

RESUMEN: El presente documento realiza un comparativo entre las escuelas de Harvard y de Chicago ante los pilares conceptuales de la Escuela Neoinstitucional. En un marco de disputa tradicional entre las escuelas de Chicago y Harvard, los desarrollos realizados por el neoinstitucionalismo pueden explicar cómo ambas escuelas del derecho antimonopolio difieren en sus propósitos, mas no en sus orígenes, pues las dos han surgido de la lucha contra los excesos perniciosos del poder de mercado y de la concentración empresarial. En ese contexto, el neoinstitucionalismo explica cómo pueden surgir los procesos de concentración empresarial y de poder de mercado, trascendiendo así las perspectivas tradicionales que se han esgrimido sobre ellos.

Palabras clave: derecho, libre competencia, Harvard, Chicago, Escuela Neoinstitucional.

* Artículo recibido el 9 de octubre de 2017 y aceptado para su publicación el 16 de junio de 2018.

** ORCID: 0000-0001-7104-1991. Investigador en la Universidad Externado de Colombia en derecho de la competencia y derecho del consumo. Abogado de la Universidad Externado de Colombia. Magíster en derecho empresarial y doctor en derecho y ciencia política, por la Universidad Autónoma de Madrid. Correo electrónico: jesus.soto@uexternado.edu.co.

*** ORCID: 0000-0002-1392-5761. Profesor investigador en la Facultad de Derecho de la Universidad de Medellín. Economista y especialista en gestión financiera de la Universidad de Medellín. Magíster en derecho económico por la Universidad Externado de Colombia. Doctorando en derecho procesal por la Universidad de Medellín. Correo electrónico:lfjaramillo@udem.edu.co.

Boletin Mexicano de Derecho Comparado, nueva serie, año LI, núm. 154, enero-abril de 2019, pp. 77-106.

Esta obra está bajo una Licencia Creative Commons Atribución-NoComercial-SinDerivar 4.0 Internacional, IIJ-UNAM. 
SUMARIO: I. Introducción. II. Aportes de la Escuela Neoinstitucional. III. La disputa en materia de libre competencia: Chicago vs. Harvard. IV. El neoinstitucionalismo como complemento de Harvard y Chicago. V. Conclusiones. VI. Bibliografia.

\section{INTRODUCGIÓN}

La protección de la libre competencia es un propósito fundamental en el cual los Estados modernos han progresado desde la aparición de la teoría económica neoclásica en la parte final del siglo XIX y de la eclosión - especialmente en Estados Unidos - de grandes monopolios en sectores sensibles como el ferroviario, el del acero y el de los hidrocarburos. En el cumplimiento de aquel propósito, se han establecido a lo largo del tiempo políticas y normas de protección de la libre competencia, en las cuales la teoría económica ha sido un elemento significativo, toda vez que como bien afirman Kovacic y Shapiro (2000: 43), la importancia económica de los términos normativos empleados es tal que la aplicación de conceptos económicos resulta esencial. Máxime, ante una realidad que demuestra que, de la misma forma que se presentan cambios en la comprensión de los elementos de la teoría económica, se presentan también cambios en la doctrina y las políticas referentes a la protección de la libre competencia, haciendo necesaria una conciliación suficientemente dinámica de ambas materias, en tiempo real.

En dicho escenario de conexión jurídico-económica, las escuelas de Chicago y de Harvard ${ }^{1}$ han protagonizado una disputa por entregas con arreglo, a la cual han rivalizado acerca de variados principios de la aludida protección. En la década discurrida entre 1960 y 1970, un grupo de estudiosos de la Universidad de Harvard afirmó que las empresas con poder de mercado estaban en capacidad $-\mathrm{y}$ de hecho eran propensas-

\footnotetext{
1 Es necesario acotar que la mención que se realiza en el presente documento, y en otros de la misma naturaleza, acerca de la "Escuela de Harvard", está basada en una terminología ampliamente reconocida en el ámbito de la protección de la libre competencia, que ha permitido, por su significado histórico, unificar un compendio de ideas sobre el derecho antitrust que no han nacido en exclusiva del bagaje de los estudiosos de las mencionadas escuelas, toda vez que se complementan con las concepciones doctrinales que han surgido en otras latitudes y en diversos centros de investigación alrededor del globo, y que les son afines.
}

Esta obra está bajo una Licencia Creative Commons

Atribución-NoComercial-SinDerivar 4.0 Internacional, IIJ-UNAM.

Boletin Mexicano de Derecho Comparado, núm. 154, enero-abril de 2019, pp. 77-106. 
a actuar de forma anticompetitiva (Hovenkamp, 2003: 920), impactando negativamente en los mercados, los competidores y los consumidores. Añadiendo que, de hecho, en virtud de las economías de escala a las cuales dichas compañías podían acceder, era necesario presumir la ilegalidad de su conducta concurrencial, pues solo de aquel modo la protección de la libre competencia podría cumplir la función social que le es connatural en defensa de los consumidores. ${ }^{2}$

Así, en el periodo enunciado, los argumentos de la escuela de Harvard se extendieron por el sistema norteamericano, impactando igualmente en otros sistemas de relevancia, ${ }^{3}$ en los cuales operó la presunción de ilegalidad de acuerdos, integraciones y conductas con una intrínseca capacidad distorsiva, más allá de que éstas pudiesen fomentar la productividad o beneficiar de alguna manera - en calidad o en precio - a los consumidores (eficiencia) (Piraino, 2007: 346). Tribunales y autoridades públicas de competencia a nivel internacional hicieron propios, mediante sus fallos, aquellos conceptos. No obstante, en la parte final de la década de los setenta dichos pronunciamientos dieron un giro hacia la adopción de los conceptos de un grupo de teóricos también relevantes de la Universidad de Chicago (Díez Estella, 2003: 34; Furse, 1996: 225; Kirkwood y Lande, 2008: 192 y ss.; Korah, 1986: 85; Soto Pineda, 2014: 351 y ss. $)^{4}$ que entendieron la defensa de la libre competencia desde una perspectiva menos "proteccionista", conforme a la cual la presunción de ilegalidad atada al poder de mercado era considerada, en sí misma, una amenaza para la competencia (Fox, 1987: 917). ${ }^{5}$

Desde aquella perspectiva doctrinal, el objetivo de la protección de la libre competencia no podía ser, bajo ningún concepto, el sugerido por Harvard, pues entendían que la impronta al respecto debía recaer en el

2 Toda vez que los consumidores justifican el esfuerzo adicional que debería emprender como prioridad la defensa de la libre competencia (Cseres, 2008: 77 y ss.) Sin olvidar otras protecciones también sugeridas por parte de la Escuela de Harvard, pues los emprendedores y las pequeñas y medianas empresas, de acuerdo con sus teorías, también merecen una defensa excepcional. (Elzinga, 1977: 1196-1202).

3 Como el de la Unión Europea, donde las motivaciones y derroteros de la materia se han visto influenciados por la mencionada escuela (Mullerat Balmaña, 2011: 20).

4 Comentarios al respecto de los lineamientos básicos de esta escuela y su influencia excepcional en el entorno estadounidense.

5 Pues de acuerdo con su concepto las empresas con poder de mercado no intentan deformar el ecosistema competitivo, pues tienen como verdadera tendencia la eficiencia. 
bienestar de los consumidores y en la atención a la eficiencia (Korah, 1994: 106) que las operaciones con impacto concurrencial, aplicadas por las empresas, debían incorporar (Díez Estella, 2003: 34; Furse, 1996: 225; Kirkwood et al., 2008: 192 y ss.; Korah, 1986: 85; Soto Pineda, 2014: 351 y ss.). ${ }^{6}$ La atención a los conceptos de la escuela de Chicago por parte de los tribunales y autoridades de competencia generó una especie de relajación en la prohibición de conductas empresariales. Aunque, del mismo modo, fomentó la realización de investigaciones de mayor profundidad, en el orden de analizar, con antelación a la declaración de la conducta como legal o ilegal, las condiciones de esta, del mercado en el cual se suscita y del impacto que podría provocar en los consumidores.

Las dos escuelas mencionadas han mantenido - y mantienen - una disputa "multidisciplinar" al interior de la protección de la libre competencia, aludiendo a diversos conceptos económicos que sustentan sus múltiples enfoques jurídico-concurrenciales, a pesar de que, con claridad, dicho componente económico es más profundo en Chicago que en Harvard. Tal ha sido el alcance de las teorías de ambas escuelas que la argumentación en sede judicial, y ante autoridades públicas de competencia alrededor del globo, han girado durante los últimos treinta y cinco años, de forma extendida y recurrente, en torno a sus tesis, alimentando la divergencia y la concepción de que en el marco de una disputa en materia de libre competencia uno de los imperativos, es el de elección y defensa de los argumentos de una u otra escuela.

Frente a los elementos propuestos por las escuelas de Harvard y Chicago como referentes de la política y normas protectoras de la competencia, desde hace algún tiempo — "los 80" — se ha planteado igualmente un corriente post-Chicago, en la cual se ha reconsiderado la teoría que intenta explicar, desde los postulados de las dos escuelas mencionadas, los comportamientos considerados anticompetitivos. De tal modo, se han presentado múltiples cambios que demuestran que - tal y como afirma Kaplow (1987: 190) - los postulados esgrimidos por la escuela de Chicago son insuficientes, desde la teoría de los precios, para explicar las nuevas condiciones en las que se desarrolla la economía y el derecho de la

\footnotetext{
6 El debate acerca de los objetivos de la protección de la libre competencia ha sido recurrente en los últimos veinte años, impactando aún en nuestros días. Ejemplos de aquel debate pueden encontrarse.
}

Esta obra está bajo una Licencia Creative Commons

Atribución-NoComercial-SinDerivar 4.0 Internacional, IIJ-UNAM.

Boletin Mexicano de Derecho Comparado, núm. 154, enero-abril de 2019, pp. 77-106. 
competencia. A lo anterior el mismo autor (Kaplow, 1987: 190) añade que las mejoras en la teoría microeconómica desde la compresión de las imperfecciones del mercado han permitido pasar de un análisis estático a un análisis dinámico de este.

En ese sentido, el desarrollo de la teoría microeconómica no puede lograrse sin la comprensión actual del mercado. Los productos, las actividades económicas, los recursos, entre otros criterios fundamentales para el sistema económico, han variado sustancialmente, requiriendo el despliegue de nuevas teorías que determinen la construcción de la normativa en la competencia (Miranda Londoño y Gutiérrez Rodríguez, 2006: 299).

Desde esta perspectiva, es necesario replantearse el concepto de mercado, trascendiendo y complementando la concepción neoclásica de este con la concepción neoinstitucional. Conceptos como costos de transacción, especificidad de activos, contratos, entre los más recurridos por esta escuela, pueden ser de gran ayuda para comprender el comportamiento de las empresas desde su funcionamiento como unidades productivas o como conjunto de firmas que hacen parte del mercado. ${ }^{7}$

Es por ello que desde el presente artículo se pretende mostrar la pertinencia de la Escuela Neoinstitucional para el derecho de la libre competencia, toda vez que, como se verá, con sus conceptos y postulados se complementan las hipótesis y razonamientos de las escuelas de Harvard y Chicago, favoreciendo así una mejor comprensión del comportamiento de los agentes del mercado, especialmente aquellos de carácter empresarial.

\section{Aportes DE LA EsGuela NeOINSTITUGional}

El neoinstitucionalismo es una escuela del pensamiento económico que, superando la noción del mercado, bajo unas leyes "naturales" no explícitas, argumenta las razones por las cuales se conforman las empresas - desde un punto de vista que supera la mera aglutinación de factores y la reducción de costos contables - y el papel que estas desarrollan en el espacio en el cual coexisten, denominado mercado. Como referente de este punto de vista acerca de la empresa y el mercado, Coase, en su texto "La naturaleza de la empresa", expresa que "un economista cree que el

7 Una mejor comprensión de esta dualidad se dará en el punto II.1, el cual explica los fundamentos del neoinstitucionalismo desde los costos de transacción. 
sistema económico está coordinado por el mecanismo de los precios y que la sociedad no es una organización sino un organismo" (Coase, 1996: 30).

Es posible descifrar esta afirmación, entendiendo que el mercado no es simplemente resultado de la acción del mecanismo de precios. Argumento que encaja en los de la escuela de Chicago, dado su paradigma de la eficiencia, operativo al advertir que situaciones como las economías de escala (Church and Ware, 2000: 58) ${ }^{8}$ o de alcance (Church and Ware, 2000: 58) determinan fuertemente el comportamiento de las empresas en el mercado. Pero ¿estas consideraciones desde la estructura de costos son las que definen en última instancia las decisiones de las empresas en el mercado? No. Los costos no solamente están asociados con el uso de los factores productivos incorporados en los bienes. También, están asociados con los riesgos derivados de la contratación y uso de dichos factores productivos (riesgo que sería extremadamente bajo si este factor estuviera en manos del productor de un bien o servicio), los cuales están determinados por las veces que se contraten los factores y el tiempo que duren dichos contratos.

Esta observación realizada por Coase (1996: 34) va conformando un concepto fundamental para la Escuela Neoinstitucional: los costos de transacción. Estos están definidos como aquellos asociados con el intercambio de bienes y/o servicios, en el entendido de que i) debe buscarse quién quiera comprar o vender el bien y/o servicio; ii) debe lograrse el arreglo que permita materializar el acuerdo, y como último punto iii) debe ejecutarse el acuerdo (Cooter y Ulen, 1998: 120 y 121).

Ante la presencia de estos costos de transacción, se vislumbra que las empresas pueden incurrir en aquellos, bien cuando estén negociando entre ellas, o bien cuando estén llevando a cabo los procesos de "intercambio de bienes y servicios de manera interna". A manera de ejemplo, una empresa que produce un bien y que requiera comprar la materia prima a un proveedor, no estaría sujeta en exclusiva al precio como mecanismo de mercado (en donde tendría que determinar con quién negociar; cuál sería la mejor forma de establecer y cerrar esta negociación y cómo reaccionar ante imprevistos frente a lo pactado en la negociación), siendo estos costos de transacción derivados de la interacción propiamente dicha con dicho

8 La economía de escala es aquella en donde en el largo plazo el costo promedio es menor mientras la producción se incrementa.

9 Una economía de alcance se define como aquella en donde es más barato producir dos bienes o servicios conjuntamente que producirlos cada uno en plantas diferente.

Esta obra está bajo una Licencia Creative Commons

Atribución-NoComercial-SinDerivar 4.0 Internacional, IIJ-UNAM.

Boletín Mexicano de Derecho Comparado, núm. 154, enero-abril de 2019, pp. 77-106. 
mercado. Y es que también puede estar sujeto a otros costos de transacción, asociados con el funcionamiento interno de los procesos productivos de la empresa. Así, Coase (1996: 40) explica que el crecimiento de una empresa tiene tendencia a progresar si:

a) Se reducen los costos de transacción al aumentar el número de transacciones.

b) Se reduce la probabilidad de que el empresario cometa errores conforme aumentan las transacciones.

c) Es menor el aumento de los precios de los factores requeridos en la producción de mayor tamaño.

$\mathrm{Al}$ tenor de aquella doctrina, vale la pena profundizar, a continuación, en las características de los costos de transacción.

\section{Algunas características de los costos de transacción}

Enunciada la presencia de los costos de transacción y su influencia en el tamaño de la empresa, en donde se afirma que el aumento o reducción de los costos de transacción determina aquel, cabe preguntarse: ¿existen circunstancias que determinen tales costos?

$\mathrm{Al}$ respecto, Cooter y Ulen (1998, 121-123) argumentan que la variación de los costos de transacción, los cuales son fundamentos de la Escuela Neoinstitucional, se presenta así:

- En relación con los costos de búsqueda, cuando el bien o servicio es de características particulares o singulares, presenta un mayor costo de transacción. En sentido contrario, si un bien es de condiciones muy generales u homogéneas, los costos de transacción asociados con este son más bajos.

- Con respecto a los costos asociados al arreglo o negociación, la información y posibilidades de cooperar en la concreción de aquella es fundamental. Si la información es de fácil acceso y pública, este costo es relativamente bajo. Sin embargo, si la información no es clara, ni oportuna, o es de difícil acceso, el costo se incrementa.

- Por último, el costo asociado al cumplimiento del acuerdo se da cuando se necesita de un periodo de tiempo para llevarlo a cabo. Cuando 
este se da instantáneamente, es decir, inmediata o muy rápidamente luego del intercambio, este costo de transacción es casi nulo. En caso contrario, es decir, cuando se necesita un seguimiento en el tiempo luego del intercambio, el costo es mayor.

Como se puede observar a partir de la definición de los costos de transacción, elementos diferentes a los costos contables o asociados con la producción o prestación de un bien o servicio determinan el comportamiento de los agentes económicos en el mercado, puesto que ellos, en virtud de la experiencia que adquieren en cada transacción, van ajustando sus acciones y perfilan el comportamiento de las actividades económicas.

Un elemento que juega un papel fundamental en la elaboración de la teoría neoinstitucional es la especificidad de los activos, toda vez que de esta se desprenden una serie de integraciones y acciones que las empresas llevan a cabo con el propósito de maximizar su beneficio en la busqueda de reducción de sus costos de transacción.

El análisis de puntos como la especificidad de los activos según Joskow (1996: 166) ha dado pie a la reevaluación de la política antimonopólica. Por ejemplo, cuando se hacen inversiones perdurables en el tiempo, bajo un esquema de incertidumbre sobre el mantenimiento y cumplimiento de lo pactado, se reestructura la forma en la que se organizan las instituciones en el mercado.

Es así como Joskow y Schmalensee en su estudio Markets for Power: An Analisys of Electric Utility Deregulation, elaborado en 1983, encontraron que la determinación de la estructura del mercado de energía eléctrica en Estados Unidos, de la época, estaba determinado por situaciones como las inversiones específicas, las relaciones contractuales según la regulación estatal y el tipo de tecnología que se empleaba en la actividad relacionada con la energía eléctrica. Aquellos determinaron que cuando se presentan inversiones en activos específicos, el mecanismo de mercado no tiene mayor utilidad, puesto que en aquel escenario se pasaría de un mercado $e x$ ante fragmentado, a un mercado ex post (luego de la negociación) con un número reducido de participantes, dándole especial poder a aquel que pueda aprovechar la ventaja del activo específico.

Es por ello que una de las ventajas que se tiene al integrar verticalmente un conjunto de actividades es reducir el costo de transacción asociado a ellas. Lo que hace bastante ventajosa esta práctica entre las dife- 
rentes empresas. Al entrar los activos específicos como un elemento que influye en la integración vertical de una actividad económica frente a la negociación de mercado, es conveniente hablar sobre tal especificidad.

\section{Especificidad de los activos}

Williamson (1989: 65) explica cuatro tipos de especificidad de los activos: especificidad del sitio; especificidad de los activos físicos; especificidad de los activos humanos, y especificidad de activos dedicados. Estos conllevan a que se forme una estrecha relación entre las partes o productores que llevan a cabo transacciones económicas con el propósito de concentrar aquellos activos que permiten desarrollar actividades estratégicas dentro de la empresa. Así, cuando las empresas están haciendo inversiones y llevan a cabo contratos sobre activos específicos, están buscando ahorrar costos, puesto que están "asegurando" la propiedad de estos activos mediante la seguridad acerca de la continuidad de las actividades económicas.

Para citar un ejemplo en donde la especificidad de los activos juega un papel fundamental en la conformación de estructuras concentradas que fomentan el monopolio, citaremos (Church y Ware, 2000: 70) el caso de Aluminiun Company of America (Alcoa). Esta compañía, aprovechando dos tipos de especificidades (de sitio y de activos físicos), construyó un monopolio sobre la producción de aluminio, dado que para la producción de esta materia prima resulta necesario disponer de bauxita, cuyas propiedades dependen de cada yacimiento; a su vez, estos están dispersos por diferentes áreas geográficas, requiriendo además métodos de fundición propios para cada tipo de bauxita, que garanticen un aluminio de óptima calidad.

Siguiendo este ejemplo, se puede tomar como complemento del mismo, también, una actividad en donde la especificidad de los activos juega un papel fundamental en la conformación de la industria, que generalmente es de estructura oligopólica o monopólica: la industria del cemento, que requiere centralizar las plantas productoras cerca de las fuentes de los minerales requeridos para su obtención, como la arcilla y la cal, además de las fuentes de carbón mineral, que es utilizado como combustible para los hornos que sirven para la incineración de la arcilla y la caliza.

Tal especificidad de los activos es fuente de oportunismo y comportamientos no develados u ocultos de una de las partes que interviene en una 
negociación. Como así sucede en los casos en los cuales un activo específico no está bajo la propiedad de quien más lo valora. Este oportunismo y comportamiento no develado aumenta los costos de transacción, lo cual también dificulta los acuerdos o contratos que se crean para hacer uso de tales activos, dado que a través del contrato no se pueden prever de manera efectiva todas las posibles contingencias derivadas del uso de los activos específicos, siendo esta última consideración un aspecto que hace mucho más atractiva una estructura organizacional que integre verticalmente todos los activos específicos en la empresa.

\section{Contratos ${ }^{10}$}

Derivado de la situación expuesta anteriormente, en la cual se explicó la relación de la especificidad de los activos con la tendencia a integrar estos en una sola estructura empresarial y por tanto fomentar la concentración en el mercado, una de las alternativas que se ha planteado es la desconcentración de las actividades productivas por medio de contratos que permitan una participación uniforme de los competidores en el mercado. Así, un contrato está inmerso en un sistema donde, como lo explica Williamson (1989: 40), están implicados puntos como la planeación, una promesa, la competencia y la gobernación (estructura u orden al interior de las firmas). Para determinar la efectividad o no de aquel, es necesario relacionar los siguientes puntos que magistralmente Williamson conjuga: la racionalidad limitada, ${ }^{11}$ el oportunismo ${ }^{12}$ y la especificidad de los activos.

Así, la presencia o ausencia de cada una de estas características en una negociación o actividad productiva en concreto, determina el mejor proceso de contratación. Pudiendo ser aquel proceso, precisamente, la planeación, la promesa, la competencia y la gobernación. Estos son a saber:

10 Cabe resaltar que el término "contrato" para este escrito no debe entenderse estrictamente desde el punto de vista legal, en donde dos o más partes suscriben un documento o acuerdan verbalmente obligaciones y acciones que conllevan al cumplimiento de lo acordado, sino como el arreglo o disposición de las partes para llevar a cabo de la mejor manera (con el menor costo de transacción) una actividad económica.

11 La racionalidad limitada está definida como la imposibilidad de conocer todos los determinantes de una situación, lo cual conlleva a tener información limitada sobre una situación en detrimento de las utilidades o beneficios esperados de ella.

12 El oportunismo es la acción no develada de una de las partes, aprovechando la falta de información o cualquier otro limitante que exista en una transacción.

Esta obra está bajo una Licencia Creative Commons

Atribución-NoComercial-SinDerivar 4.0 Internacional, IIJ-UNAM.

Boletín Mexicano de Derecho Comparado, núm. 154, enero-abril de 2019, pp. 77-106. 
Esta revista forma parte del acervo de la Biblioteca Jurídica Virtual del Instituto de Investigaciones Jurídicas de la UNAM http://www.juridicas.unam.mx/ https://biblio.juridicas.unam.mx/bjv https://revistas.juridicas.unam.mx/

DOI: http://dx.doi.org/10.22201/iij.24484873e.2019.154.14138

ASPECTOS COMUNES DE LAS ESGUELAS DE CHICAGO Y HARVARD...

\begin{tabular}{|l|l|l|l|}
\hline Racionalidad limitada & \multicolumn{1}{|c|}{ Oportunismo } & \multicolumn{1}{|c|}{$\begin{array}{c}\text { Especificidad } \\
\text { de los activos }\end{array}$} & $\begin{array}{c}\text { Proceso de contratación } \\
\text { implicado }\end{array}$ \\
\hline Ausente & Presente & Presente & Planeación \\
\hline Presente & Ausente & Presente & Promesa \\
\hline Presente & Presente & Ausente & Competencia \\
\hline Presente & Presente & Presente & Gobernación \\
\hline
\end{tabular}

FUENTE: Williamson (1989: 41).

Aunque esta tabla contiene elementos propios de la teoría neoinstitucional, estos no son incompatibles con la teoría neoclásica de la firma, la cual guarda una estrecha relación con los argumentos de la escuela de Chicago. Por ejemplo, desde la teoría neoclásica, las empresas pueden generar o no cuasi-rentas (Signes de Mesa et al., 2013: 69), ${ }^{13}$ que están determinadas con la especificidad de los activos empleados en una actividad económica. Es esta circunstancia propia de la naturaleza de dichos activos (su especificidad), la que exige un mecanismo que disminuya la posibilidad de ejercer una conducta que atente contra la libre competencia con su consecuente efecto negativo, para los competidores y los consumidores.

Así, el contrato (entendido como el mecanismo que permite que las partes en una transacción ajusten su comportamiento futuro) (Church y Ware, 2000: 72) permite incluir ${ }^{14}$ en la negociación el conjunto de in-

13 Una cuasi-renta puede definirse desde estos dos puntos de vista: el primero, que se expresa como la diferencia entre los ingresos totales y los costos evitables (aquellos en los que no se incurre cuando se elige una alternativa de producción), la cual determina la permanencia o no de la empresa en el mercado. La segunda definición se refiere a la inversión que se haga en activos específicos, de donde se toma que la cuasi-renta es la diferencia entre el valor de uso actual de un activo frente a su uso alternativo o también llamado costo de oportunidad. Por ende, el costo de oportunidad estimado antes de una negociación determina los términos de dicha negociación en materia de inversiones en activos específicos, así como, la continuidad de dicha relación económica (Church y Ware, 2000: 70)

14 Es necesario precisar que los contratos pueden ser completos o incompletos, en aras de manifestar que los contratos no son la solución esperada a los problemas como especificidad de activos, oportunismo, o presencia de costos de transacción. Así, cuando los contratos no presentan ningún costo de transacción no haciendo necesario su revisión y/o modificación, es porque están previstas todas las circunstancias que se puedan dar en el desarrollo del intercambio objeto del contrato. La presencia de un contrato completo en el tema que estamos tratando (costos de transacción y activos específicos) no es lo habitual, lo que indica que el contrato que se emplea en estos casos es un contrato incompleto, el cual implica que una de las partes puede tomar ventaja de la otra a través de un comportamiento oportunista, generando ineficiencias en dicho intercambio (Church y Ware, 2000: 73). 
centivos y desincentivos que evitarían los actos contrarios a la libre competencia. Cuando se da la existencia de esos costos de transacción y especificidad de los activos, se está en presencia de contratos incompletos, abordada por la teoría homónima, que desarrolla "el impacto del marco institucional sobre el diseño del contrato, situando sus ideas en los fundamentos que estudian los efectos de la localización de los derechos de propiedad sobre la distribución del beneficio residual entre los agentes y sus incentivos a invertir" (Brousseau, Eric y Glachant, 2002: 10).

Luego de exponer los puntos centrales sobre los cuales la Escuela Neoinstitucional gira, es momento de mostrar los puntos que enfrentan a la escuela de Chicago con la de Harvard en materia de libre competencia, pues de tal manera se podrán identificar claramente las razones que originan las contraposiciones y sus orígenes.

\section{LA DISPUTA EN MATERIA DE LIBRE COMPETENCIA: CHICAGO VS. HARVARD}

Siguiendo la dirección trazada en la parte introductoria del presente texto, a continuación, se abordarán con mayor profundidad los aportes que han realizado a la defensa de la libre competencia las escuelas de Chicago y Harvard, con el objetivo de clarificar el origen y naturaleza de las desavenencias doctrinales jurídico-económicas que les han enfrentado.

En ese sentido, es necesario iniciar este esquema de las disputas entre las dos escuelas enunciadas, exponiendo el que es considerado por los autores del presente artículo el principal desacuerdo entre ambas corrientes: el de los objetivos de la protección de la libre competencia. Disputa que influencia de forma directa la presencia de desavenencias doctrinales acerca de otros aspectos también importantes de la materia, pues teniendo puntos de partida heterogéneos, Harvard y Chicago han comprendido la aplicación de las normas antitrust desde diversas perspectivas, en valor de fines en oportunidades contrapuestos.

Así, la escuela de Chicago ha defendido, al tenor de la fuerte influencia que ha tenido en su seno la escuela económica neoclásica, que los conceptos económicos y, específicamente, la eficiencia, entendida como un compendio de criterios dirigidos a crear un entorno de bienestar en

Esta obra está bajo una Licencia Creative Commons

Atribución-NoComercial-SinDerivar 4.0 Internacional, IIJ-UNAM.

Boletín Mexicano de Derecho Comparado, núm. 154, enero-abril de 2019, pp. 77-106. 
los consumidores, son la respuesta a la razón de ser de la protección de la libre competencia. ${ }^{15}$ En su opinión, la búsqueda de la eficiencia económica - en términos locativos, productivos y dinámicos - ha configurado siempre el objetivo exclusivo de la materia (Posner, 2001: 24), ${ }^{16}$ ya que favorece la protección de la competencia propiamente dicha y sus elementos connaturales (Kolasky, 2004; Parikh y Majumdar, 2012: 253). ${ }^{17} \mathrm{La}$ maximización de la riqueza - que es a su vez una derivación de sistemas económicos saludables y eficientes (Jones y Sufrin, 2008: 3-16) — es, desde su óptica, comprobación de aquel derrotero, ya que mediante aquella se multiplican las posibilidades de acceder a bienes y servicios, con motivo del aumento en la producción, el crecimiento propio del consumo y la reducción congénita de costos y de precios (Bork, 1966: 7).

Argumentos que van en contraposición de los razonamientos esgrimidos por Harvard en lo también referido a los objetivos de las normas de competencia, ya que la afinidad jurídico-pública de la materia, desde su punto de vista, condiciona los derroteros de esta. La eficiencia económica, encubierta en un fundamento "multinivel" de bienestar de los consumidores (como defiende Chicago), le ha parecido insuficiente, de forma recurrente, a la escuela en cuestión. Máxime cuando los destinatarios de las deformidades concurrenciales de los mercados son los agentes de menor dimensión y capacidad, que por su posición requieren de una defensa excepcional por parte de las normas de competencia, alcanzable, en exclusiva, mediante la disposición taxativa de derroteros de corte más social que económico. Así, la escuela de Harvard arguye que la de-

$15 \mathrm{Al}$ respecto del vínculo entre la economía y la protección de la competencia, sobre el cual se ha elaborado la teoría en torno a la cual gira la eficiencia y el bienestar del consumidor como fin exclusivo de la defensa (Van der Bergh y Camesasca, 2001). Siendo también valiosos los comentarios que pueden hallarse al respecto de la cuestión en Ak$\operatorname{man}(2007)$.

16 Concebido en el estándar "bienestar del consumidor" (consumer welfare). Este sector de la doctrina ha afirmado que los profesionales con sensatez involucrados con la protección de la libre competencia, indistintamente de su rol, como litigantes, "comisarios" académicos, jueces, etcétera, no deben albergar dudas acerca de que mediante la aplicación de la normativa que sustenta la protección enunciada, se busca, en exclusiva, la consolidación de un entorno económico eficiente que repercuta en la totalidad de agentes involucrados con la dinámica económica.

17 Defensores de aquella concepción especialmente económica de los objetivos de la defensa de la libre competencia. 
fensa de la libre competencia debe buscar proteger, de forma concreta y precisa, al agente propiamente dicho, competidor y/o consumidor (Ana, 2008, II: 1114-1115), y no a la competencia en sentido abstracto, ya que dicho concepto es "peligrosamente" indeterminado. De ahí que la aplicación de la normativa antitrust deba perseguir, de acuerdo a su doctrina, el logro de derroteros tangibles como (i) la descentralización del poder económico (Gerber, 2004; Pace, 2007: 39-41; Scherer y Ross, 1990: 18), ${ }^{18}$ (ii) la distribución equitativa del bienestar, (iii) la tutela de aspectos sociopolíticos (Landolt, 2006: 22-31; Motta 2004, 26 y 27), ${ }^{19}$ (iv) la defensa de la libertad (Amato, 1997: 2-3; Hawk, 1997: 1670-1675), ${ }^{20}$ (v) la protección de los competidores (D. J. Gerber, 1998: 232-265; Whish, 2008: 17 y 18), ${ }^{21}$ (vi) la defensa de las empresas domésticas frente a las foráneas (Gil Ibáñez, 2005: 112; Whish, 2008: 19-23), ${ }^{22}$ (vii) la lucha contra el desempleo y los efectos inflacionarios y (viii) la protección al consumidor (Soto Pineda, 2014: 363).

El núcleo de los fundamentos esgrimidos por Harvard es de corte proteccionista, en parte, por la influencia fundamental que ha tenido en sus postulados la teoría clásica estructuralista. ${ }^{23}$ Aquello se observa con claridad en la fase primigenia de organización de los objetivos de la defensa de

18 En virtud de la desaceleración que se produce mediante la concentración de recursos y de riqueza, contrariando principios fundamentales de la protección de la competencia. Del mismo modo, véase, el asunto United states vs. Aluminum Co. Of America (en lo sucesivo Alcoa), 148 F.2d 416 (Segundo circuito, 1945), apartado 428.

19 Derrotero conectado con impactos medio ambientales, fiscales, laborales, estratégicos, entre otros. Mostrándose en contra de éste, y la sentencia del Tribunal de Justicia de las Comunidades Europeas, de 20 de septiembre de 2001, asunto C-453/99, Courage Ltd vs. Bernard Crehan y otros (en lo sucesivo Courage/Crehan). A favor del mismo, Motta (2004).

20 Ante la coyuntura de que el poder de mercado de algunos agentes económicos podría condicionar libertades (Cseres, 2005: 248-250; Whish, 2008: 20), quien alude a Jean Paul Sartre para llamar la atención acerca del peligro que enfrentan las libertades democráticas cuando se tolera el crecimiento de un "poder privado" hasta un punto en el cual se configura una fuerza incluso más poderosa que el Estado. Igualmente, Amato (1997) y Hawk (1997).

21 Reino Unido, The grocery market. The OFT's reasons for making a reference to the competition Commission, OFT 845; Directorate General For Competition, Discussion paper on the application of article 82 of the Treaty to exclusionary abuses, 2005, apartado 88.

$22 \mathrm{Y}$ el asunto Établissements Consten S.à.R.L. and Grundig-Verkaufs-GmbH Vs. La Comisión de la Comunidad Económica Europea (en lo sucesivo Consten \& Grundig, Korah, 2004: 2 y ss.).

23 Así se puede confirmar en Cournot (1897).

Esta obra está bajo una Licencia Creative Commons

Atribución-NoComercial-SinDerivar 4.0 Internacional, IIJ-UNAM.

Boletín Mexicano de Derecho Comparado, núm. 154, enero-abril de 2019, pp. 77-106. 
la libre competencia. ${ }^{24}$ Pero no sólo en aquella configuración de principios, pues igualmente la escuela en cuestión parte de una base de ilegalidad de las concentraciones de poder de mercado, sustentada en que la eficiencia y la salud del ecosistema competitivo se encuentran influenciadas por el número de agentes presentes en aquel mercado y por su dimensión (Bain, 1959; Mason, 1964). Así, la escuela interpreta que dichas concentraciones configuran una desaceleración natural de los sectores económicos en los cuales se presentan, que en virtud de su peligrosidad inherente - al configurar un terreno propicio para las conductas de corte anticompetitivo - merecen siempre una respuesta contundente por parte de la defensa de la competencia.

Partiendo de aquella premisa de ilegalidad concurrencial de las concentraciones de poder, desde Harvard han defendido la utilidad que comporta para la protección efectiva de los mercados, presumir la ilegalidad de las conductas vinculadas con aquellas. Así, este sector ha sostenido que, a pesar de que un supuesto concreto de concentración pueda generar eficiencias e incluso favorecer a los consumidores en el corto plazo, la realidad es que la verticalidad que se produce en las relaciones comerciales y en las de consumo es siempre nociva en el mediano y largo plazo (Hovenkamp, 2003: 920), generando mayores ineficiencias y proclividad al comportamiento anticompetitivo. Razón por la cual arguyen que la protección de la competencia debe otorgar a los particulares y a las pequeñas empresas ${ }^{25}$ un amparo especial sustentado en los propósitos a cumplir mediante la aplicación contundente de las normas que le sustentan (Cseres, 2008: 77 y ss.) ${ }^{26}$ en la dirección de establecer un contrapeso efectivo, en sede pública y privada, a las concentraciones de poder en el mercado.

24 Posición criticada de forma asidua. Por ejemplo, Bishop y Walker (2002: 23-27). Del mismo modo, Motta (2004: 17-30), quien defiende que a pesar de que los objetivos de política pública sean importantes para un sistema de protección como el de la competencia, la consecución de aquellos derroteros puede implicar en ocasiones dificultar la competitividad en los mercados, mediante, por ejemplo, la imposición de restricciones públicas a la competencia. Un concepto opuesto al enunciado es el que defiende Amato (1997: 119), pues este valora que los fines puramente económicos no dan respuesta a las realidades sociales que también deben enfrentar en su aplicación las normas de libre competencia.

25 El valor de la protección de emprendedores y pequeñas y medianas empresas mediante la defensa de la competencia puede encontrarse descrita con mayor amplitud en Elzinga, Kenneth (1977a: 1196-1202).

26 Pues el derecho de la competencia tiene una obligación connatural con los consumidores que no debe eludirse mediante la utilización de argumentos económicos. 
Los conceptos esgrimidos por la escuela de Harvard en materia de presunción de ilegalidad concurrencial en los casos de concentración del mercado han sido el foco principal de múltiples críticas de la llamada escuela de Chicago durante casi tres décadas (Hagen, 1958: 496-514; Kim, 2012: 52-56; Van Lennep, 1982: 40-41; McGee, 1993: 541; Takacs, 1981: 687-693). ${ }^{27}$ En ese sentido, los estudiosos de esta última línea doctrinal han manifestado que suponer la ilegalidad concurrencial con motivo de la presencia de concentraciones en el mercado, comporta mayores inconvenientes que beneficios. La concentración de acuerdo con su perspectiva puede ser el resultado de eficiencias autónomas logradas en el ejercicio competitivo. La búsqueda de la eficiencia es inherente a la política de competencia y a la actividad económica. ${ }^{28}$ Por lo que castigar a un agente que ha logrado concentrar una parte importante del mercado en el que se desenvuelve gracias a sus calidades y a la eficiencia que ha desplegado en el proceso productivo, se les ha antojado un despropósito (Korah, 1994: 106). De acuerdo con su visión, la concentración puede ser el resultado de economías de escala, economías de alcance, economías

27 A lo que se une el peligro que interpretan, existe, al centrar la protección de la libre competencia en "custodias sociales", ya que dicha dinámica dirige el sistema hacia, lo que consideran, un pernicioso proteccionismo, que se ha demostrado nocivo para la competencia gracias a los precedentes, al restringir la libertad económica y/o promover concentraciones de poder que impiden a los consumidores acceder al producto de la mejor calidad al mejor precio. Al respecto de la perdida en la libertad económica, aludida desde la tradición de Chicago. Del mismo modo, acerca de la promoción de concentraciones de poder, que perciben en la dinámica proteccionista, en razón del impulso que los sistemas de aquel corte ponen en marcha en favor de la industria doméstica (Böge 2006: 2; Rodríguez Curiel, 2002: 358). De relevancia igualmente la jurisprudencia que influenciada por la concepción "no proteccionista" defendida por la escuela de Chicago, en aplicación de los criterios aquí esgrimidos, se ha producido en la Unión Europea y en Estados Unidos. Así, en la Unión Europea, las sentencias del Tribunal de Justicia de la UE, de 26 de junio de 1999, Déménagements-Manutention Transport SA, asunto C-256/97, en su apartado 22, y de 29 de abril de 1999, y El Reino de España vs. La Comisión de las Comunidades Europeas, asunto C-342/96. En Estados Unidos, las sentencias de la Suprema Corte de los Estados Unidos, de 28 de junio de 1984, Bacchus Imports, Ltd. vs. Dias, 468 U.S. 263, y de 4 de abril de 1994, Oregon Waste Systems, Inc. v. Department of Environmental Quality of Oregon, 511 U.S. 93, 99.

28 La explicación de los fundamentos que justifican la creación de un sistema de protección de aquellos que logran generar mayores eficiencias en el proceso competitivo, de acuerdo a los fundamentos defendidos por la escuela de Chicago, puede encontrarse en Van Bael y Bellis (2010: 1212-1213), Cavanagh (2005: 207 y ss.), Gseres (2005: 207 y ss.), Marcos y Sanchez Graells (2008: 9-10), Schinkel (2007: 539-572) y Wils (2009: 1).

Esta obra está bajo una Licencia Creative Commons

Atribución-NoComercial-SinDerivar 4.0 Internacional, IIJ-UNAM.

Boletín Mexicano de Derecho Comparado, núm. 154, enero-abril de 2019, pp. 77-106. 
de aglomeración, mejoramiento de costos, etcétera. Consideraciones que impiden que pueda considerarse, per se, condenable, es decir, formar parte activa y eficaz de la dinámica connatural a la economía de mercado.

Por añadidura, desde Chicago han agregado que las razones adicionales a la eficiencia que favorecen la concentración de un mercado en pocas manos no están necesariamente ligadas a la ilegalidad. Arguyen al respecto que las adaptaciones inteligentes del mercado también pueden ocasionar concentraciones en aquellos casos en los cuales se presentan dificultades para acceder a materias primas, cuando el sector se enfrenta a una inseguridad elevada y/o excepcional o a circunstancias tales como el encarecimiento de materiales primarios. Por lo que se ratifican en sus afirmaciones acerca de las concentraciones económicas, manifestando que no deben ser atacadas debido a su simple presencia en la realidad económica. Así pues, la concentración de poder de mercado y su posible capacidad distorsiva configura una de las desavenencias más importantes entre las escuelas de Chicago y de Harvard. Aunque no la única, referida a la valoración de las condiciones y actuaciones de los agentes del mercado, ya que cada una de ellas ha defendido un modelo concreto de análisis de las conductas de mercado, dirigido a determinar la compatibilidad que aquellas tienen con el ideario de la materia, o en su caso, la ilegalidad concurrencial que comportan.

De tal modo, la escuela de Harvard ha defendido la implementación de una regla de interpretación per se por parte de las autoridades encargadas de aplicar las normas antitrust. Regla en virtud de la cual el estudio y resolución de pactos y conductas empresariales con capacidad distorsiva atiende exclusivamente a una comparativa del comportamiento objeto de análisis y la prohibición dispuesta en la norma de competencia. Generando, por tanto, que la sola ocurrencia de una conducta, al margen de los efectos que tenga o pueda tener en el mercado y de las intenciones de las partes, configure la ilegalidad concurrencial. La escuela de Harvard ha promulgado mediante la regla per se, una regla de aplicación eficiente de la normativa de referencia, con capacidad para simplificar la toma de decisiones en materia de libre competencia.

Como resultado de las primeras aproximaciones al antitrust y al impulso de la escuela de Harvard, la regla per se fue aplicada de forma dinámica y asidua en los años iniciales de la defensa de libre competencia y en las décadas centrales del siglo XX. No obstante, conllevaba un nivel de rigi- 
dez basado en la presunción de ilegalidad de todos los contratos, pactos y/o acuerdos entre empresas, sin atender a sus efectos, provocando así que casi la totalidad de acuerdos entre dos o más compañías fuesen ilegales. Presumiendo siempre que aquellos resultaban perniciosos para el ecosistema competitivo. Desde Chicago se observó con sorpresa la "inflexibilidad" de la mencionada regla, por lo que se decidió respaldar, desde sus orígenes, una norma de interpretación más flexible: la regla de la razón, basada no en la equivalencia que una actuación tuviese con la prohibición normativa, sino en los efectos que la conducta en cuestión provocase en el ecosistema competitivo. Haciendo necesarios, por tanto, análisis económicos rigurosos alusivos al mercado de referencia, a sus participantes, las cuotas de mercado que ostentan, entre otros, en la dirección de determinar su apego a la normativa antitrust o su ilegalidad. Análisis que, a pesar del desgaste y los largos periodos de estudio que comportan - criticados por la escuela de Harvard-, han sido defendidos de forma profusa por los representantes de la senda doctrinal enunciada, en alusión a diversos criterios jurídicos y económicos.

Es claro, por tanto, que las diferencias entre las escuelas de Harvard y Chicago en materia de libre competencia se han desarrollado de forma general y particular, impactando en múltiples esferas de la aplicación de las normas antitrust. Incluso en lo referido a la autonomía que debe serle atribuida a los mercados, el acuerdo ha sido esquivo, pues por un lado la escuela de Harvard ha sostenido que el mercado no tiene capacidad para autorregularse, pues ha demostrado en variadas ocasiones, debido a la complejidad y pluralidad que le es connatural, su imposibilidad para alcanzar la correcta asignación de recursos. Mientras que desde Chicago se ha defendido que el mercado debe ser autónomo, y que al margen de la envergadura de los agentes que operan en él, dicho mercado se encuentra siempre capacitado para remediar sin intromisiones las deformaciones competitivas que se presenten en su seno. Haciendo por tanto innecesaria la intervención de "la Administración". Este sector de la doctrina manifiesta que la intrusión de supervisores adscritos al sector público a modo de cooperación, apoyo o comportamientos de similar naturaleza es siempre nociva para los mercados y los consumidores, siendo por tanto necesario promover un marco de actuación en el cual sean evitadas aquellas actuaciones a como dé lugar.

Esta obra está bajo una Licencia Creative Commons

Atribución-NoComercial-SinDerivar 4.0 Internacional, IIJ-UNAM.

Boletín Mexicano de Derecho Comparado, núm. 154, enero-abril de 2019, pp. 77-106. 
Chicago defiende, por tanto, en lo alusivo a la defensa de la libre competencia, la aptitud natural y autónoma de los mercados para reorganizarse en aquellos casos en los cuales se presentan "alteraciones concurrenciales" (Hovenkamp, 2001: 267)..$^{29}$ Los tribunales, las agencias y autoridades públicas encargadas de aplicar la normativa de referencia no han demostrado, de acuerdo con su perspectiva, suficiente idoneidad para contener y remediar fallos en el ecosistema competitivo, ${ }^{30}$ por lo que otorgar poderes de intervención a aquellos que no han mostrado más aptitudes que aquellas que tienen los mercados en ejercicio de su autonomía, se les antoja un despropósito (Fox, 1987: 264). ${ }^{31}$ La doctrina adscrita a la escuela de Chicago defiende desde variadas direcciones la aptitud natural del mercado a autorregularse. Las sanciones de acuerdo con su doctrina no deben surgir de una autoridad, pues las impone el mismo mercado de forma fluida en ejercicio de su función de selección, otorgando recompensas a los oferentes de mayor eficiencia, y castigos, tales como la expulsión del mercado, a aquellos que no evidencien aptitudes competitivas idóneas, al no promover mediante sus actuaciones la búsqueda de la eficiencia.

Harvard, por su parte, ha entendido que la autonomía del mercado defendida por la escuela de Chicago no atiende adecuadamente a la realidad de aquel. Y es aquí dónde comprende que existe una paradoja de la economía liberal, ya que para que la economía imperante en los mercados se desarrolle en marcos de libertad, es imprescindible que los poderes públicos intervengan mediante regulación, remedios y sanciones que prevengan que comportamientos contrarios al proceso competitivo, se "apropien" del mercado. Las imperfecciones del mercado no pueden ser obviadas, de acuerdo con esta tradición, máxime cuando aquellas han sido de mayor

29 Debido a lo cual, la participación de terceros agentes - como las agencias de regulación, jueces y autoridades administrativas - solo está justificada, de acuerdo con la escuela de Chicago, cuando es claro, tras un estudio exhaustivo, que la conducta anticompetitiva amenaza el bienestar de los consumidores.

30 Acerca de la temática enunciada, véase Martin (1993). Del mismo modo, Rubinfeld (2009: 457-469) y Schinkel y Tuinstra (2004: 3 y ss.).

31 Pues según su óptica, contrariu sensu de la presunción negativa de la escuela de Harvard que entiende que las empresas de gran magnitud siempre tendrán la tendencia de incrementar su poder por medio de deformaciones del sistema competitivo, la verdadera tendencia de las compañías más poderosas es la de "ser eficientes". Siendo aquella la razón por la cual no es necesaria la participación de terceros agentes cuando se presentan desequilibrios competitivos. 
profundidad sin la intervención de los mencionados poderes públicos, ya que en aquellos casos la liberalidad ha redundado en mercados concentrados proclives a poner en práctica comportamientos inmoderados.

El llamado paradigma de Bain (1956: 293 y ss.), denominado ECD, surgido de la tradición de Harvard, ha venido a fundamentar dicha afirmación. De acuerdo con él, la estructura de una industria es la que motiva su conducta. Conllevando dicha conducta, a su vez, un desempeño concreto. Así, el número de agentes en dicha industria, la estructura de costos, los niveles de concentración vertical, entre otros, deben ser tomados en cuenta para definir la estructura, que a su vez determina conductas como la publicidad, la innovación, las inversiones o la fijación de precios, repercutiendo en desempeños concretos eficientes o ineficientes, favorables o desfavorables para con la actividad competitiva y el bienestar común (González Mejía, 2011: 74).

Así, la tradición de Harvard ha defendido la intervención como respuesta a las dinámicas que mediante el paradigma ECD demuestran un ejercicio pernicioso de la competencia, ya que el desempeño concurrencial del mercado es resultado de la conjunción de la estructura, la conducta y el desempeño. Chicago, por el contrario, ha entendido que la confianza en la competencia se menoscaba mediante intervenciones de los poderes públicos, ya que el "dejar hacer y dejar pasar" de la teoría del Laissez faire francés debe ser el fundamento principal de cualquier economía no enfocada en el "fatal proteccionismo", pues el amparo de aspectos sociales como los defendidos desde Harvard como objetivos del antitrust, es siempre una secuela transversal de los sistemas económicos eficientes. ${ }^{32}$

Una vez identificado por qué las escuelas de Harvard y Chicago se contraponen, y enunciados los puntos centrales sobre los cuales descansa la teoría neoinstitucional, se planteará cómo esta última puede identificar situaciones que sirven de puente entre aquellas, y que pueden mejorar la comprensión de la presencia de situaciones que originan los elementos centrales de Harvard y Chicago respectivamente: el trinomio estructuraconducta-desempeño; y la eficiencia (locativa, productiva y dinámica).

32 De hecho, la escuela de Chicago arguye que las salvaguardas particulares pueden perjudicar a los consumidores y a las PYMES incluso más que la protección macro de la eficiencia. Crane, Daniel, "Antitrust Enforcement during National Crises: An Unhappy History”, en Armengol I Gasul (2009: 5-7) y Crane (2008: 3); y en aplicación al ejemplo latinoamericano (Marcos, 2010: 457-467).

Esta obra está bajo una Licencia Creative Commons

Atribución-NoComercial-SinDerivar 4.0 Internacional, IIJ-UNAM.

Boletín Mexicano de Derecho Comparado, núm. 154, enero-abril de 2019, pp. 77-106. 
Esta revista forma parte del acervo de la Biblioteca Jurídica Virtual del Instituto de Investigaciones Jurídicas de la UNAM

\section{EL NEOINSTITUCIONALISMO GOMO GOMPLEMENTO DE HARVARD Y CHICAGO}

La Escuela Neoinstitucional desde sus fundamentos puede ser planteada como una escuela que puede presentar una visión complementaria de las escuelas de Harvard y Chicago. En efecto, si tomamos los fundamentos de Harvard, partiendo de que las concentraciones y el comportamiento per se son contrarios a la libre competencia (cosa que es discutible desde Chicago), y los de Chicago, cuyos argumentos esgrimen tales situaciones probables de restricciones a la competencia como una oportunidad para lograr eficiencias que sean provechosas para el mercado, entonces la Escuela Neoinstitucional, desde la explicación que da sobre la naturaleza de los activos que intervienen en una actividad económica, como también desde los tipos de costos de representan las transacciones en esta, contribuye a una mejor compresión de los fundamentos de las escuelas de Harvard y Chicago.

En efecto, es claro, desde la teoría de los activos específicos, que muchas actividades económicas, dada su naturaleza, tienden a conformar monopolios. Como por ejemplo los naturales. Siendo claro a ese tenor, igualmente, que, aunque se pueda estar frente a una competencia en el mercado, la misma no es garantía de que no haya poder de mercado, debido a los altos costos de transacción. También es claro que para que pueda darse un beneficio en la actividad de forma tal que los costos de producción y transacción se reduzcan, son necesarias principalmente integraciones verticales. Por tanto, creemos que la cuestión sobre la protección de la libre competencia está llamada a profundizar sobre los elementos de juicio que permitan tomar la mejor decisión en aras de cumplir con los propósitos de eficiencia y mejoramiento del excedente del consumidor.

Es por ello, que desde hace un tiempo se está promoviendo un "movimiento" post Chicago, en donde se empieza a relacionar la competencia con temas como el "comportamiento estratégico", entendido como el comportamiento puesto en marcha por un actor del mercado con miras a hacer menos atractiva la competencia en aquel (Hovenkamp, 1985: 260). De igual forma, Chicago debe dejar a un lado el apego a la eficiencia en el mercado, la cual se centra en "el comportamiento de largo plazo y en los mercados en donde los activos se transfieren de una empresa a otra a muy bajo costo" (Hovenkamp, 1985: 264). La situa- 
Esta revista forma parte del acervo de la Biblioteca Jurídica Virtual del Instituto de Investigaciones Jurídicas de la UNAM

ción contraria, es decir, en la cual no es fácil transferir dichos activos, es denominada "costos hundidos", ${ }^{33}$ que están relacionados fuertemente con la especificidad de los activos; de nuevo un concepto emanado de la Escuela Neoinstitucional.

A partir de las anteriores anotaciones, podemos decir que las preocupaciones de las escuelas de Harvard y Chicago tienen asidero, puesto que, si se hiciera un estudio concienzudo y profundo, el mismo, seguramente, haría evidente que en muchos sectores de la economía se presentan situaciones que atentan contra la libre competencia, las cuales se manifiestan a través de acuerdos, actos o abusos de posición de dominio, como también por medio de elevados niveles de poder de mercado. Pero, también es cierto que muchas de estas situaciones son el resultado de características intrínsecas a la actividad económica, que la Escuela Neoinstitucional se encarga de analizar. El siguiente gráfico ilustra la posición que ocuparía la teoría neoinstucional en el análisis antimonopolio frente a cada escuela.

\section{Gráfica 1. Posición de la Escuela Neoinstitucional en el análisis del derecho antimonopolio}

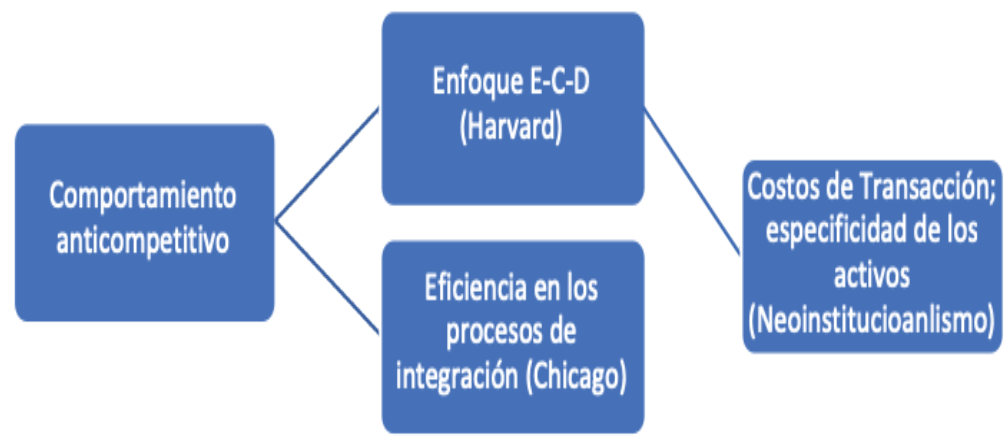

FUENTE: elaboración propia.

33 Los costos hundidos se definen como aquellos costos que no se pueden recuperar con la operación de la empresa o cuando se decide que esta salga del mercado. Así, los costos hundidos crean una barrera de entrada, pues generan un incremento en los costos y riesgos para los participantes en el mercado. Church y Ware (2000: 512).

Esta obra está bajo una Licencia Creative Commons

Atribución-NoComercial-SinDerivar 4.0 Internacional, IIJ-UNAM.

Boletín Mexicano de Derecho Comparado, núm. 154, enero-abril de 2019, pp. 77-106. 
Es la posición que tiene la Escuela Neoinstitucional en el análisis de las situaciones que atentan contra la libre competencia propuesta en la gráfica 1, la que origina críticas a la posición eficientista de la escuela de Chicago mediante la cual estableció su crítica a las restricciones a las integraciones verticales. De manera análoga, Salinger ${ }^{34}$ explica que las críticas que Chicago hizo hacia la política de control de integraciones que efectuaba el Departamento de Justicia de los Estados Unidos hacia las integraciones verticales tuvieron eco en la literatura sobre las integraciones verticales, esgrimiendo que estas pueden generar eficiencias en los costos de producción, que con posterioridad pueden igualmente trasladarse a los consumidores.

Es la constante evolución de la teoría económica la que ha permitido hacer las diferentes críticas a los modelos vigentes, lo cual ha repercutido en el ejercicio institucional de la protección de la competencia, no siendo los aportes de la Escuela Neoinstitucional una excepción.

Ahora bien, no sólo la inclusión de los puntos centrales del neoinstitucionalismo ayuda a mejorar la comprensión del comportamiento de las empresas en el mercado dadas sus características referentes a los activos y la forma en la que realizan acuerdos entre ellos. También, dicha inclusión puede colaborar en una mejor toma de decisiones por parte de la autoridad competente en materia de protección de la competencia, dado que los sistemas legales implican costos, así como los errores ${ }^{35}$ generados por dicha política de protección de la competencia y aquellos incluidos en la decisión que deban asumir (Carlton, 2007: 160).

Por último, frente a esta situación, la aplicación de los fundamentos de la Escuela Neoinstitucional en el derecho de la competencia debe llevar a

34 Para 1968, el Departamento de Justicia de los Estados Unidos (DOJ por sus siglas en inglés) suscribe una guía de integraciones en la cual explica que las integraciones verticales tienden a crear barreras de entrada, por lo cual este tipo de prácticas era visto con recelo y trataba de evitarse (Salinger, Michael, Roger D. Blair y D. Daniel Sokol, 2015: 554).

35 Los errores que acarrean costos cuando se toma una decisión en materia de protección de la competencia son el error tipo I y el error tipo II. El tipo I también llamado "falso positivo" se presenta cuando luego de un análisis sobre las utilidades que una empresa obtiene dada una economía de escala, se concluye que la empresa tiene poder de mercado, no siendo así en la realidad. El error tipo II o "falso negativo" se da cuando se asume que una empresa no tiene poder de mercado cuando en realidad sí lo posee. Este error se puede dar cuando la autoridad antimonopolio no controla una acción que perjudica la eficiencia (Gerardin et al., 2012: 84). 
reflexionar sobre el papel que juegan las normas e instituciones dedicadas a ello y su efectividad en el logro de su propósito. En este sentido, Joskow (1996: 98) expone los siguientes puntos frente a las expectativas que se le han otorgado a dichas normas e instituciones:

1) Las normas e instituciones no se diseñaron para identificar y eliminar todas las imperfecciones del mercado. Ese tipo de examen minucioso no puede ser exitoso dados los enormes costos de transacción que involucran dichas imperfecciones.

2) Para el caso de los Estados Unidos de América, la política antimonopolio es básicamente un sistema de disuasión y no un sistema de regulación. Los incentivos que operan sobre las firmas deben desprenderse - y entenderse - de/desde un sistema de reglas que provengan de los costos potenciales que se aumentan con acciones dañinas, de las restricciones administrativas sobre su comportamiento, de otras atenuantes similares como la diversificación o de y para ciertas infracciones.

3) Si el sistema de disuasión actúa eficientemente, la política antimonopolio debe dar señales claras sobre cuál es el límite de acción que tiene una empresa sobre sus actos, de tal forma que determine dónde termina su comportamiento legal y dónde comienza su comportamiento ilegal.

4) Los tribunales no poseen expertos para evaluar conductas económicas anticompetitivas. Frente a esto, las agencias antimonopolio se encuentran en mejor posición que los tribunales, puesto que disponen de herramientas y personal con preparación económica que aporta una mayor cantidad de elementos de juicio.

Aunque estos puntos planteados por Joskow, como él mismo esgrime, son para las leyes antimonopolio de los Estados Unidos de América, no dejan de ser un referente, pues el direccionamiento a nivel global de las normas que protegen la competencia proviene de este país.

Por último, si conjugáramos los elementos centrales discutidos en este escrito (costos de transacción, especificidad de activos, contratos, normas e instituciones que protegen la competencia) con el objetivo de que encuadrasen en una nueva visión de ellos dentro de la política de protección de la competencia, obtendríamos el siguiente gráfico: 
Esta revista forma parte del acervo de la Biblioteca Jurídica Virtual del Instituto de Investigaciones Jurídicas de la UNAM http://www.juridicas.unam.mx/

Gráfica 2. Fases de desarrollo del derecho antimonopolio

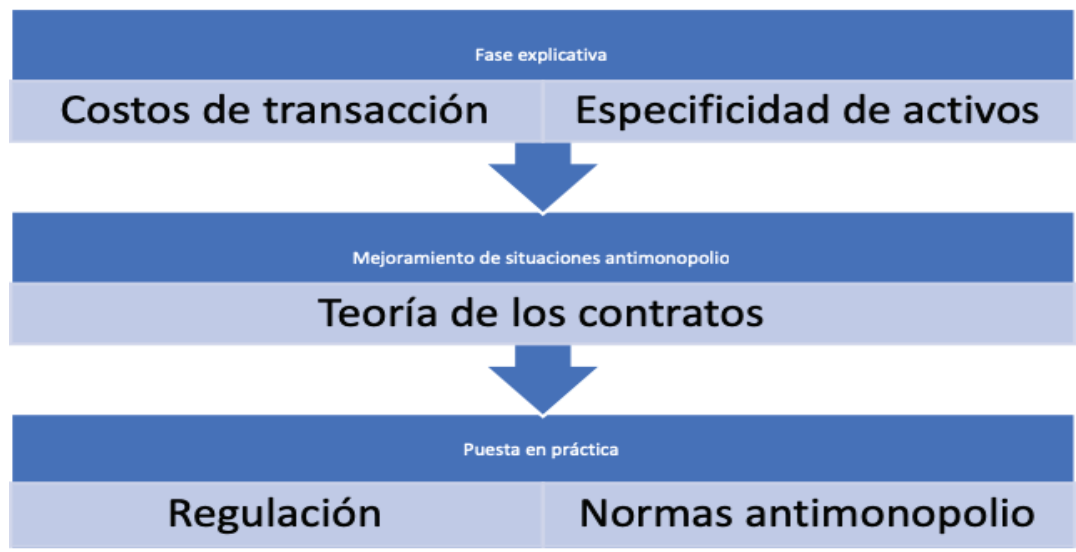

FUENTE: elaboración propia.

\section{CONCLUSiOnes}

El neoinstitucionalismo ha sido una de las escuelas económicas que más rápida evolución ha presentado en las últimas décadas. Desde su estudio primigenio sobre los costos de transacción, expuesto por Coase en 1937, pasando por los derechos de propiedad, así como por la especificidad de los activos, su evolución ha llegado hasta la teoría de los contratos, la cual fue galardonada en 2016 en cabeza de los profesores Holmström y Hart.

En virtud de aquella realidad, no representa mayor riesgo expresar que los fundamentos de la Escuela Neoinstitucional presentan una utilidad novedosa en cuanto a la explicación de ciertas situaciones de mercado que las escuelas de Harvard y Chicago han desestimado en sus análisis, y que las han situado en puntos habitualmente extremos, muy a pesar de que dichas situaciones de mercado son comunes a los puntos de partida del análisis de ambas corrientes doctrinales.

Así las cosas, criterios como la especificidad de los activos o los costos de transacción son aspectos comunes a los principios de análisis de Har- 
vard y Chicago, pues los primeros son connaturales a los segundos. Así, Harvard parte de que la relación estructura-conducta-desempeño permite situaciones anticompetitivas per se, mientras que Chicago argumenta que dicha situación permite eficiencias. En ambos casos, están presentes las características estudiadas por el neoinstitucionalismo como determinantes de tales situaciones (la anticompetitiva y la eficiente).

En tal sentido, los fundamentos del neoinstitucionalismo sirven de punto de análisis para ambas escuelas, permitiendo un nuevo enfoque dentro del estudio del derecho de la competencia comprendido en las denominadas escuelas post Chicago.

Como los fundamentos teóricos del neoinstitucionalismo expresan situaciones que están fuertemente ancladas en la naturaleza de las actividades económicas (por ejemplo, especificidad de activos, costos de transacción), toma fuerza en el ámbito académico una nueva visión del derecho de la competencia, la cual, en lugar de dar por sentado que la intervención de las autoridades, se pone en práctica con el objetivo de remediar tales fallas de mercado y permite centrarse en mitigar el impacto que dichas actividades contrarias a la libre competencia están generando.

\section{BIBLIOGRAFÍA}

Amato, Giuliano, 1997, Antitrust and the Bounds of Power. The Dilemma of Liberal Democracy in the History of the Market, Oxford, Hart Publishing. ARMengol I GASUl, Oriol, 2009, "Derecho de la competencia en tiempos de crisis", Gaceta Furídica de la Competencia y de la Unión Europea.

BAIN, Joe, 1956, Barriers to New Competition. Their Carácter and Consequences in Manufacturing Industries, Cambridge, Sage Publications.

BAIN, Joe, 1959, Industrial Organization, Nueva York, Wiley.

BÖGE, Ulf, 2006, "State Imposed Restrictions of Competition and Competition Advocacy", Challenges of Addressing State Imposed or Facilitated Restraints, ABA Spring Meeting.

BORK, Robert, 1966, "Legislative Intent and the Policy of the Sherman Act", Fournal of Law and Economics, 9.

Brousseau, Eric y Glachant, Jean-Michael, 2002, The Economics of Contracts and the Renewal of Economics, The Economics of Contracts: Theory and Applications, Cambridge, Cambridge University Press.

Esta obra está bajo una Licencia Creative Commons

Atribución-NoComercial-SinDerivar 4.0 Internacional, IIJ-UNAM.

Boletín Mexicano de Derecho Comparado, núm. 154, enero-abril de 2019, pp. 77-106. 
Esta revista forma parte del acervo de la Biblioteca Jurídica Virtual del Instituto de Investigaciones Jurídicas de la UNAM

Carlton y Dennis, W., 2007, "Does Antitrust Need to Be Modernized?", American Economic Association, 21.

Cavanagh, Edward, 2005, "Antitrust Remedies Revisited", Oregon Law Review.

Church, Jeffrey y WARE, Roger, 2000, Industrial Organization, Boston, McGraw-Hill.

COASE, R.H., 1996, "La naturaleza de la empresa", en WiLliamson Oliver, E. y Winter SidNey, G. (eds.), La naturaleza de la empresa: origenes, evolución y desarrollo, México, Fondo de Cultura Económica.

Cooter, Robert y Ulen, Thomas, 1998, Derecho y economía, México, Fondo de Gultura Económica.

Cournot, Antoine Augustin, 1897, Researchers into the Mathematical Principles of the Theory of Wealth, Nueva York, MacMillan.

CRANe, Daniel, 2008, "Antitrust Enforcement during National Crises: An Unhappy History", GCP The Online Magazine for Global Competition Policy.

Cseres, Katalin Judit, 2005, Competition Law and Consumer Protection, La Haya, Kluwer Law International.

Cseres, Katalin Judit, 2008, "What Has Competition Done for Consumers in Liberalised Markets?", The Competition Law Review, 4.

Díez Estella, Fernando, 2003, "Los objetivos del derecho antitrust", Gaceta Jurídica de la Unión Europea y de la Competencia.

ElzINGA, Kenneth, 1977a, "The Goal of Antitrust: Other Than Competition and Efficiency, What Else Counts?", University of Pennsylvania Law Review, 125.

ElzINGA, Kenneth, 1977b, "The Goal of Antitrust: Other Than Competition and Efficiency", University of Pennsylvania Law Review, 6.

Fox, Eleanor, 1987, "The Battle for the Soul of Antitrust", California Law Reviere, 75.

Furse, Mark, 1996, "The Role of Competition Policy: A Survey", European Competition Law Review, 17.

Gerber, David, J, 1998, Law and Competition in Twentieth Century Europe: Protecting Prometheus, Nueva York, Oxford University Press.

GERBER, Davis, 2004, "Fairness in Competition Law: European and U,S, Experience", Conference on Fairness and Asian Competition Laws.

GIL IBAÑEZ, José Luis, 2005, "La comisión y la aplicación del derecho comunitario de la competencia”, en GARRIDO ESPÁ, Luis (ed.), La defensa 
de la competencia por los órganos judiciales: el Reglamento CE 1/2003, Madrid. Consejo General del Poder Judicial.

Ginsburg, Douglas, 2006, "An Introduction to Bork (1966)", Competition Policy International, 2.

GonzÁlez MejíA, Juan Felipe y Rosero Aguilar, María Lauren, 2011, "Análisis de estructura, conducta y desempeño del subsector de La Confitería, en el área metropolitana de Cali, 2002-2010”, Entramado, 7.

Hagen, Everett, 1958, "An Economic Justification of Protectionism", Quaterly Journal of Economics, 72.

HaWK, Barry, 1997, "Giuliano Amato, "Antitrust and the Bounds of Power", Fordham International Law fournal, 21.

Hovenkamp, Herbert, 1985, "Antitrust after Chicago", Michigan Law Review Association, 84.

Hovenkamp, Herbert, 2001, "Post-Chicago Antitrust: A Review and Critique", Columbia Business Law Review.

Hovenkamp, Herbert, 2003, "The Rationalization of Antitrust", Harvard Law Review, 116.

Jones, Alison y Sufrin, Brenda, 2008, EC Competition Law, Text, Cases and Materials, Nueva York, Oxford University Press.

Joskow, Paul, 1996, "La especificidad de los activos y la estructura de las relaciones verticales: pruebas empíricas", en WILLIAMSON, Oliver y WINTER, Sidney (eds.), La naturaleza de la empresa: orígenes, evolución y desarrollo, México, Fondo de Cultura Económica.

KAPLOW, Louis, 1987, "Antitrust, Law \& Economics, and the Courts, Law and Contemporary Problems", Duke University School of Law, 50.

Kyung-Hoon, Kim, 2012, "Rising Protectionism in Emerging Countries", SERI Quarterly.

KIRKWOOD, John y LANDE, Robert, 2008, "The Fundamental Goal of Antitrust: Protecting Consumers, Not Increasing Efficiency", Notre Dame Law Reviere, 84.

KOLASKY, William, 2004, "What is Competition? A Comparison of US and EU Perspective", Wilmer Cutler Pickering Hale and Dorr Antitrust Series.

KorAH, Valentine, 1986, "EEC Competition Policy, Legal Form or Economic Efficiency", Current Legal Problems, 39.

KORAH, Valentine, 1994, An Introductory Guide to EC Law and Practice, Londres, Sweet \& Maxwell. 
Korah, Valentine, 2004, An Introductory Guide to EC Law and Practice, Oxford, Hart Publishing.

Kovacic E., William y SHAPIRO, Carl, 2000, Antitrust Policy: A Century of Economic and Legal Thinking, Minneapolis.

Kovacic E., William y Shapiro, Carl, 1990, "The Antitrust Paradox Revisted: Robert Bork and the Transformation of Modern Antitrust Policy", Wayne Law Journal.

LANDOLT, Philip Louis, 2006, Modernised EC Competition Law in International Arbitration, La Haya, Kluwer Law International.

Van LenneP, Emile, 1982, "Protectionism vs. Economic Policy", The OECD Observer.

Marcos, Francisco y SÁnchez Graells, Albert, 2008, "Damages for Breach of the EC Antitrust Rules: Harmonising Tort Law through the Back Door?", Indret: Revista para el Análisis del Derecho.

Marcos, Francisco y SÁnchez Graells, Albert, 2010, "En defensa de la competencia pero en contra del mercado: la paradoja antitrust en latinoamérica. Notas a propósito de De León, I", Revista de Derecho de la Competencia y la Distribución, 7.

Mason, Edward, 1964, Economic Concentration and the Monopoly Problem, Cambridge, Harvard University Press.

MaGeE, Robert, 1993, "An Economic Analysis of Protectionism in the United States with Implications for International Trade in Europe", The George Washington Fournal of International Law and Economics, 26.

Miranda Londoño, Alfonso y Gutiérrez RodríGez, Juan David, 2006, "Fundamentos económicos del derecho de la competencia: los beneficios del monopolios vs. los de beneficios de la competencia", $D e^{-}$ recho de la Competencia, 2.

MotTa, Massimo, 2004, Competition Policy, Theory and Practice, Nueva York, Cambridge University Press.

Mullerat Balmaña, Ramón, 2011, "El arbitraje y el derecho de la competencia", Revista Derecho de los Negocios, 248.

Pace, Lorenzo Federico, 2007, Derecho europeo de la competencia, prohibiciones antitrust, control de concentraciones y procedimientos de aplicación, Madrid, Barcelona, Marcial Pons.

PARIKH, Jenisha y MAJUMDAR, Kashmira, 2012, "Competition Law and the Consumer Law: Identifying the Contours in Light of the Case of Belaire Owners Association vs. DLF”, Nujs Law Review. 
PirAinO, Thomas, 2007, "Reconciling the Harvard and Chicago Schools: A New Antitrust Approach for the 21 st Century", Indiana Law fournal, 82. Posner, Richard, 1979, "The Chicago School of Antitrust Analysis", University of Pennsylvania Law Review, 27.

Posner, Richard, 2001, Antitrust Law, The University of Chicago Press. RodríGUez Curiel, Wenceslao, 2002, "Las ayudas públicas en la ley de defensa de la competencia”, en GONZÁLEZ-ORÚs, Jerónimo Maillo y BENEYTO PÉREZ, José María (coords.), El nuevo derecho comunitario y español de la competencia: descentralización, análisis económico y cooperación internacional, Madrid, Bosch.

RubinfELD, Daniel, 2009, "Evaluating Antitrust Enforcement: Economic Foundations", Annual Proceedings of the Fordham Competition Law Institute, International Antitrust Law \& Policy, Nueva York, Juris Publishing.

Scherer, Frederic M. y Ross, David R., 1990, Industrial Market Structure and Economic Performance, Boston, Houghton Mifflin.

SCHINKEL, Maarten Pieter, 2007, "Effective Cartel Enforcement in Europe", Law and Economics Reviere, 30.

Schinkel, Maarten Pieter y Tuinstra, Jan, 2004, "Imperfect Competition Law Enforcement", CeNDEF.

Signes DE MESA, Juan Ignacio et al., 2013, Derecho de la competencia, Madrid, Thomson Reuters.

Soto PinedA, Jesús Alfonso, 2014, "La protección al consumidor como finalidad primordial de la defensa de la competencia: la experiencia de Estados Unidos, la Unión Europea y Colombia", Díkaion 23.

TAKACS, Wendy, 1981, "Pressures for Protectionism: An Empirical Analysis", Economic Inquiry, 19.

VAN BAEL, Ivo y BELLIS, Jean-François, 2010, Competition Law of the European Community, Holanda, Kluwer Law International, Alphen aan den Rijn.

VIDE, Ana, 2008, Derecho español de la competencia, comentarios a la Ley 15/2007, Real Decreto 261/2008 y Ley 1/2002, t. II, en OdRiozola, Miguel (dir.) e IRISSARRY, Belén (coord.), Barcelona, Bosch.

Whish, Richard, 2008, Competition Law, Londres, Oxford University Press. WiLliamson, Oliver, 1989, Las instituciones económicas del capitalismo, México, Fondo de Cultura Económica.

WILS, Wouter, P. J., 2009, "The Relationship between Public Antitrust Enforcement and Private Actions for Damages", World Competition: Law and Economics Review, 32. 